\title{
Automated determination of red cell methaemoglobin reductase activity by a continuous-flow system for screening hereditary methaemoglobinaemia
}

\author{
K. TANISHIMA, N. FUKUDA, M. TAKESHITA, Y. TAKIZAWA, T. KITAMURA, \\ AND Y. YONEYAMA
}

From the Department of Medical Technology, Kanazawa University School of Paramedicine, Kanazawa, Japan 920

SUMMARY A flow diagram for the automated determination of ferricyanide reductase activity in red blood cells was prepared in the modules from AutoAnalyzer AA I (Technicon Instruments Inc). Ferricyanide reductase assay can be substituted for assay of cytochrome $b_{5}$ reductase (EC 1.6.2.2), which plays a major role in reducing methaemoglobin in erythrocytes, and is defective specifically in the erythrocytes of patients with hereditary methaemoglobinaemia.

The effective sampling rate of the analysis is $30 / \mathrm{h}$, and less than $0.05 \mathrm{ml}$ of whole blood is required. Interference of haemoglobin with absorption by potassium ferricyanide at $420 \mathrm{~nm}$ is effectively excluded by dialysis. This automated method was compared with the accepted diaphorase method, and it distinguished clearly the ferricyanide reductase activity of cord bloods from that of adult bloods. The activity of the blood from a patient with hereditary methaemoglobinaemia was only residual.

It is suggested that the method is useful as a mass screening test for hereditary methaemoglobinaemia.

The deficiency of erythrocyte NADH-methaemoglobin reductase has been documented in many other patients with congenital methaemoglobinaemia and reviewed by Hsieh and Jaffe (1975). Recently, many investigators have considered NADH-cytochrome $b_{5}$ reductase to be the major enzyme catalysing the reduction of methaemoglobin in vivo and hereditary methaemoglobinaemia to be due to an abnormality of this enzyme (Hultquist and Passon, 1971; Sugita et al., 1971; Kuma and Inomata, 1972). In general, the patients encounter little difficulty although they have slate-grey cyanosis. However, Dine (1956) found congenital methaemoglobinaemia with mental retardation. Recently, it has been evident that a small but significant number have mental retardation, and the early detection of hereditary methaemoglobinaemia in the newborn has been of great value (Fialkow et al., 1965; Leroux et al., 1975).

Methaemoglobin reductase activity in red blood cells is generally measured as 'diaphorase' by using

Received for publication 18 September 1978 the dye 2,6-dichlorophenolindophenol (DCIP) as an electron acceptor. However, diaphorase is resolved into various fractions by ion-exchange chromatography, and only one of these fractions shows the activity of cytochrome $b_{5}$ reductase. For this reason it is most satisfactory to measure the cytochrome $b_{5}$ reductase activity for the specific diagnosis of hereditary methaemoglobinaemia. With regard to the assay of cytochrome $b_{5}$ reductase, it is difficult and time-consuming to prepare cytochrome $b_{5}$ as a terminal electron acceptor from tissue sources. We reported previously the ferricyanide reductase assay substituted for the cytochrome $b_{5}$ reductase assay, which had the advantage of using a chemical reagent as substrate electron acceptor and specificity for cytochrome $b_{5}$ reductase activity, but involved excluding haemoglobin from the haemolysate using a CM-cellulose column I (Tanishima et al., 1978).

The purpose of this report is to describe exclusion of interference by haemoglobin with the absorption by potassium ferricyanide at $420 \mathrm{~nm}$ using a continuous-flow dialysing system, and to establish a simple and rapid automated assay for screening hereditary methaemoglobinaemia. 


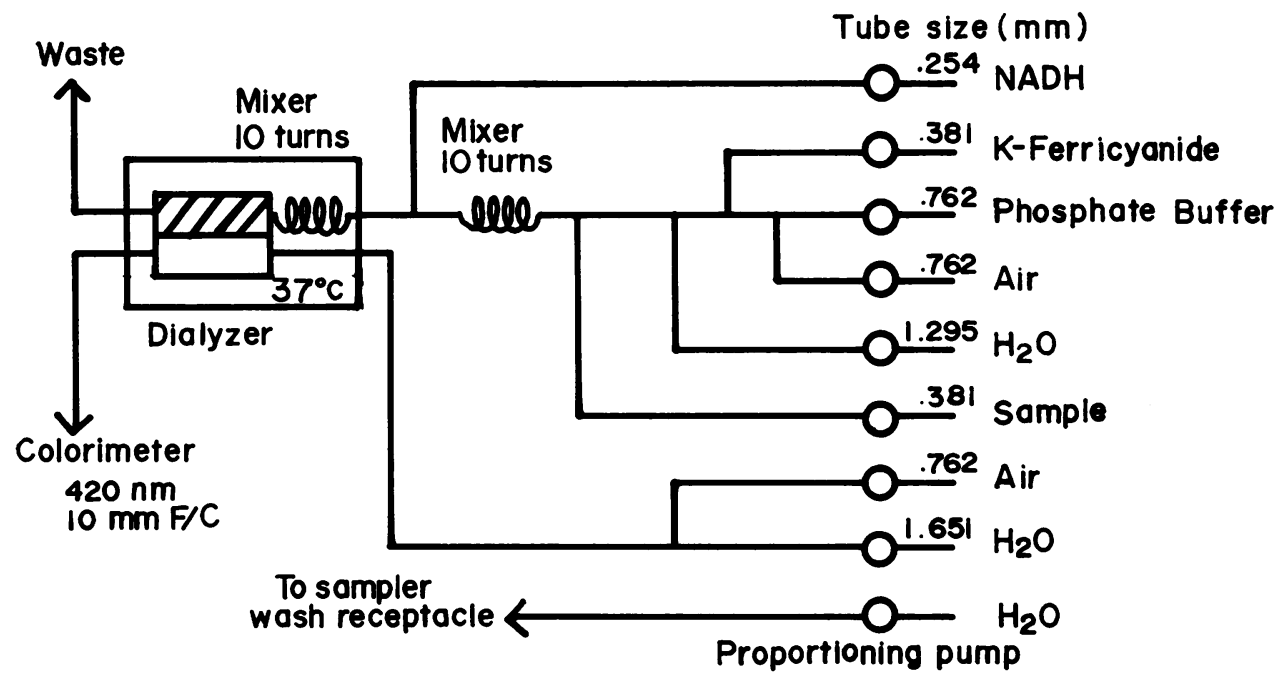

Fig. 1 Flow diagram of manifold in AutoAnalyzer AA I for methaemoglobin reductase assay using potassium ferricyanide as an electron acceptor (ferricyanide reductase assay).

\section{Material and methods}

\section{BLOOD SAMPLES}

Normal human blood samples were obtained from healthy volunteer students and university officials. Cord blood specimens were from the Department of Obstetrics and Gynaecology, Kanazawa University Hospital. Blood samples for the screening test came from the Central Clinical Laboratory of the same hospital. The blood samples from a patient with hereditary methaemoglobinaemia were kindly provided by Dr Hirano (Hirano et al., 1976), of the Department of Internal Medicine, Medical School of Nagoya Health Science University.

\section{AUTOMATED METHOD FOR MEASUREMENT OF} FERRICYANIDE REDUCTASE ACTIVITY

A flow diagram for the automated determination of ferricyanide reductase activity was prepared in the modules of the AutoAnalyzer AA I (Technicon Instruments Inc) (Fig. 1). Volumes of $0.05 \mathrm{ml}$ of whole blood oxidised with $5 \mu 1$ of $0.2 \mathrm{~mol} / 1$ sodium nitrite are haemolysed with $0.45 \mathrm{ml}$ volumes of distilled water and placed in sample cups. The haemolysate is mixed with phosphate buffer, potassium ferricyanide, and NADH in the stream. The mixed sample (donor) stream enters one plate of the dialyser in a $37^{\circ} \mathrm{C}$ water bath. The recipient stream of water flowing through the other plate receives the diffusible potassium ferricyanide from the sample stream, which remains unreduced after the reaction. This stream is then analysed by the spectrophotometric method at $420 \mathrm{~nm}$ for potassium ferricyanide. An effective sampling rate is $30 / \mathrm{h}$.

Reagents are as follows: $0.5 \mathrm{~mol} / 1$ sodium phosphate buffer at $\mathrm{pH} 7 \cdot 5 ; 15 \mathrm{mmol} / 1$ potassium ferricyanide; $10 \mathrm{mmol} / 1 \mathrm{NADH}$; all in solution containing $0.3 \mathrm{ml} \mathrm{Brij-35/1}$.

The ferricyanide reductase activity was expressed as international units (IU) per $\mathrm{ml}$ of erythrocytes according to the following equation:

$$
\frac{\mathrm{E}}{1020} \times \frac{\mathrm{V}}{\mathrm{t}} \times \frac{10^{5}}{\mathrm{Ht} \times \mathrm{v}}
$$

where $\mathrm{E}=$ the difference in absorption between ferricyanide and distilled water at $420 \mathrm{~nm}, \mathrm{~V}=$ volume of reaction mixture $=1.6 \mathrm{ml}, \mathrm{t}=$ reaction time $=2$ minutes, $\mathrm{Ht}=$ haematocrit value $(\%)$, $\mathrm{v}=$ volume of blood sample $=0.01 \mathrm{ml}, 1020=$ molar extinction coefficient of potassium ferricyanide at $420 \mathrm{~nm}$.

The limit of resolution for the difference between total and unreacted substrates ( $\Delta$ substrate) was $15 \mathrm{nmol}$ per minute, when a diluted solution of the purified enzyme was assayed with the AutoAnalyzer instrumentation using potassium ferricyanide as an electron acceptor ( $\Delta$ OD was 0.01 in spectrophotometry).

DETERMINATION OF HAEMATOCRIT VALUE The haematocrit value was determined according to the microhaematocrit method using the Haematocrit centrifuge RC-24BN (Tomy Seiko Co. Ltd) at $11000 \mathrm{rpm}$ for 5 minutes. 
MANUAL METHODS FOR MEASURING

REDUCTASE ACTIVITY

NADH-ferricyanide reductase activity of a partially purified enzyme from normal red cells and NADHdiaphorase activity of a haemolysate using 2,6dichlorophenolindophenol as an electron acceptor were assayed according to the methods reported previously by Tanishima et al. (1978). In this report, linearity, effect of $\mathrm{pH}$ and kinetics of ferricyanide reductase activity were studied.

PURIFIED CYTOCHROME b5 REDUCTASE

Cytochrome $b_{5}$ reductase for use in fundamental studies and quality control was purified from normal human red cell haemolysate by DE-32 column chromatography as reported previously (Tanishima et al., 1978).

\section{Results}

STUDIES ON FUNDAMENTAL PROBLEMS

Linearity for ferricyanide reductase activity in both the manual reference method and the automated test method were studied by assaying the enzyme purified from normal red cell haemolysate (Fig. 2).

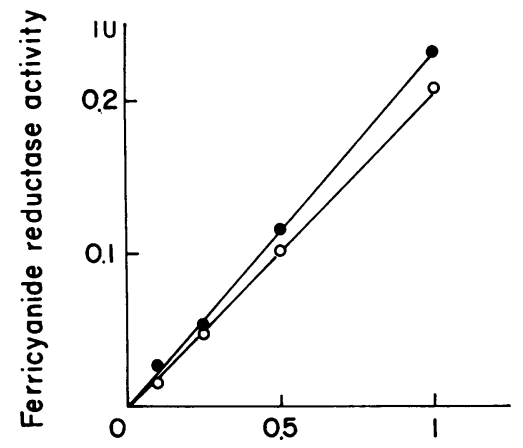

Concentration of enzyme $(\mathrm{mg} / \mathrm{ml})$

Fig. 2 Standard curves for purified cytochrome $b_{5}$ reductase activity by AutoAnalyzer and manual ferricyanide reductase assay methods.

The enzyme was purified from normal human red blood cells by DE-32 column chromatography. Dilutions were performed with phosphate buffer. The assays were carried out by both the manual (reference) method and the automated (test) method described in the text: $I U=$ international units per $\mathrm{ml}$ of diluted solution of enzyme; $\bigcirc-0$ manual assay; $\bigcirc-0$ Auto Analyzer assay.

The reduction rate of potassium ferricyanide by the enzyme with NADH $v$ concentrations of the enzyme was linear in both methods. The time course for the enzyme reaction is shown in Figure 3. In the manual

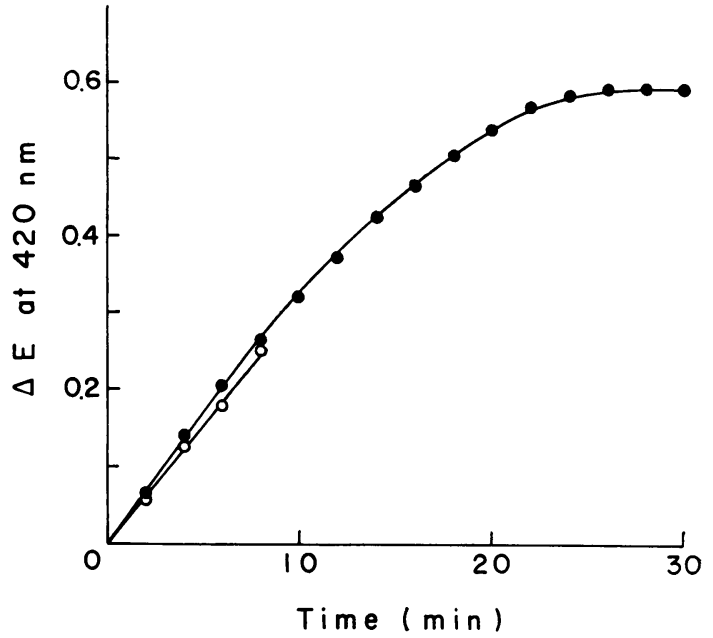

Fig. 3 Time course in ferricyanide reductase assay. The reduction of potassium ferricyanide by the purified cytochrome $b_{5}$ reductase $(1 \mathrm{mg}$ per $1.5 \mathrm{ml}$ of reaction mixture as protein) was recorded by Hitachi Model 200-20 recording spectrophotometer at $420 \mathrm{~nm}$ for 30 minutes by the manual method, and was tested in the AutoAnalyzer system described in the text, respectively: $\Delta E=$ differences of absorbance for corresponding time; $\bigcirc-1$ manual method; $\bigcirc-\bigcirc$ AutoAnalyzer method.

reference method, the initial rate of reduction of potassium ferricyanide, as an electron acceptor, was essentially linear with time for 7 minutes. In the AutoAnalyzer test method, the same result was obtained by increasing the number of reaction-mixing coils in the heating bath. From these results, consumption of substrate is about $0.35 \mu \mathrm{mol}$ in 7 minutes in $1.5 \mathrm{ml}$ of reaction mixture containing $1.5 \mu \mathrm{mol}$ of potassium ferricyanide, and the reaction rate is linear over this change in substrate concentration.

MEASUREMENT OF ENZYME ACTIVITY IN NORMAL RED CELL HAEMOLYSATE BY TEST METHOD

Figure 4 shows the relationship between the concentration of haemoglobin in the haemolysate to be placed in the sample cup and ferricyanide reductase activity in the test method. The linear relationship was observed up to $30 \mathrm{mg} / \mathrm{dl}$ of the final concentration of haemoglobin.

A recovery test was performed on the haemolysate with $20 \mathrm{mg} / \mathrm{dl}$ of haemoglobin. When the purified enzyme, which had approximately the same activity as the haemolysate, was added to the haemolysate, 


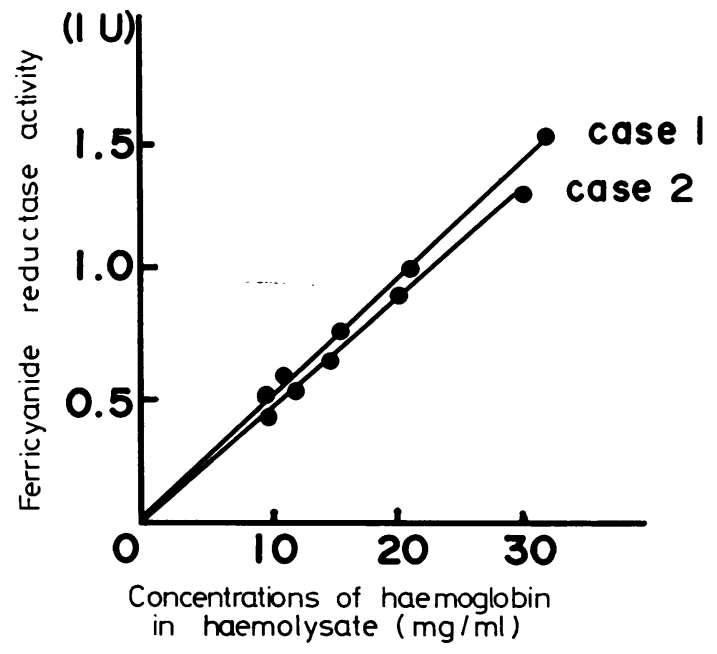

Fig. 4 Ferricyanide reductase activity in normal red cell haemolysate by AutoAnalyzer method: $I U=$ international units per $\mathrm{ml}$ of diluted haemolysate.

recovery of ferricyanide reductase activity in the test method was $92 \%$.

\section{PRECISION}

Ten samples from each of three normal human adults were tested on the same working days. The mean ferricyanide reductase activity in the test method, standard deviation (SD), and coefficient of variation (CV) in percent are as follows:

$3.75 \pm 0.13$ international units (IU) per $\mathrm{ml}$ of erythrocytes, $3.5 \%$

$3.46 \pm 0.11$ international units (IU) per $\mathrm{ml}$ of erythrocytes, $3 \cdot 2 \%$

$3.98 \pm 0.21$ international units (IU) per $\mathrm{ml}$ of erythrocytes, $5 \cdot 3 \%$

With respect to reproducibility day to day, the heparinised whole blood samples from three normal adults were stored at $4^{\circ} \mathrm{C}$. Volumes of $0.05 \mathrm{ml}$ were haemolysed with $0.45 \mathrm{ml}$ volumes of distilled water and placed in sample cups for each day's assay. The automated assay of these samples was carried out 10 times during two working months. The mean \pm SD was $3.45 \pm 0.11,3.68 \pm 0.14$, and $4 \cdot 11 \pm 0 \cdot 18$ (IU per $\mathrm{ml}$ of erythrocytes), and CV was $3.2 \%, 3 \cdot 8 \%$, and $4.4 \%$, respectively.

\section{COMPARISON WITH CONVENTIONAL}

\section{DIAPHORASE METHOD}

Twenty-three samples of heparinised whole blood from normal adults and 14 samples of cord blood were assayed by the conventional diaphorase method (manual) and the automated test method. The results are shown in Figure 5.
It can be seen in the results from both the automated method and the diaphorase method that the values of activity in cord blood are significantly lower than those in adult blood. Only a little overlapping of the values in cord blood with those in adult blood is observed for ferricyanide reductase activity in the test method. In the diaphorase system, however, a certain overlapping between the values from these two blood groups is seen.

The mean ferricyanide reductase activity of blood samples from 23 normal adults was $4.0 \pm 0.63 \mathrm{IU}$ per $\mathrm{ml}$ of erythrocytes, and that from 14 cord bloods was $1.95 \pm 0.43$ IU per $\mathrm{ml}$ of erythrocytes. In the blood sample from a patient with hereditary methaemoglobinaemia, the ferricyanide reductase activity was $0.56 \mathrm{IU}$ per $\mathrm{ml}$ of erythrocytes.

\section{APPLICATION TO SCREENING}

Ferricyanide reductase activities of 1466 human blood samples from our hospital were analysed by our automated test method. Figure 6 shows the distribution of the values. From the linearity in plotting cumulative frequency on probability paper, it was evident that these values of ferricyanide reductase activities were quasi-Gaussian.

\section{Discussion}

Since Gibson (1948) and Scott and Griffith (1959) reported a congenital deficiency of an enzyme catalysing the reduction of methaemoglobin in erythrocytes, it has been an important problem to determine the methaemoglobin reductase activity for the detection of this disease. Various methods have been reported for determining reductase activity, for example, the diaphorase method by Scott (1960), the cytochrome $b_{5}$ reductase method by Hultquist and Passon (1971), and the ferrihaemoglobin reductase method by Hegesh et al. (1968). The ferricyanide reductase method previously described by us (Tanishima et al., 1978) not only correlated well with accepted methods but also met the requirement of a simple and specific test for the diagnosis of hereditary methaemoglobinaemia, because of its easy application to routine work in the laboratory without any special reagents or expensive equipment.

Results by the automated method offer more rapid analysis and mass screening of the enzyme deficiency in hereditary methaemoglobinaemia. The screening of hereditary methaemoglobinaemia is important for the early detection of the disease and its prevention in infants. Previous observations record that a small but significant proportion of the cases of congenital enzymopenic methaemoglobinaemia is associated with a progressive neurological disorder with mental retardation causing death at a 

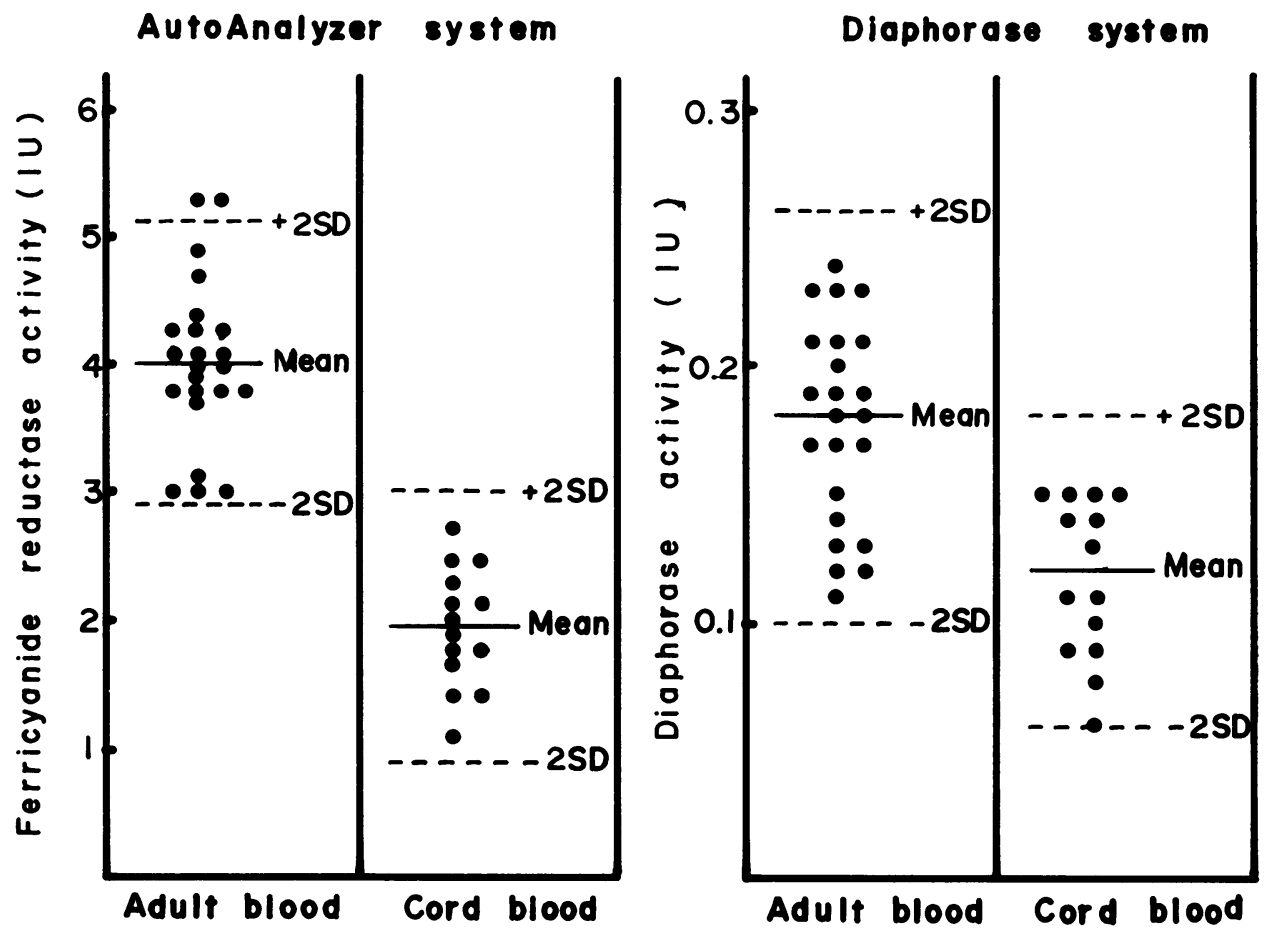

Fig. 5 Comparison of methaemoglobin reductase activity of cord and adult blood by AutoAnalyzer ferricyanide reductase assay with that by manual diaphorase assay. The activity was measured for the same individuals at the same time by both methods: $S D=$ standard deviation; $I U=$ international units per $m l$ of erythrocytes.

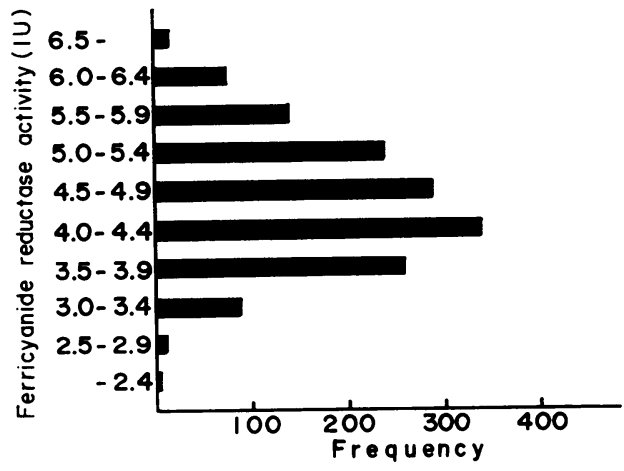

Fig. 6 Frequency distribution of ferricyanide reductase activities of red cell haemolysate from 1466 samples by AutoAnalyzer. $I U=$ international units per $\mathrm{ml}$ of erythrocytes.

young age (Leroux et al., 1975). The detection of heterozygous carriers is a problem because this inheritance is considered to be a simple recessive trait. We used cord blood to simulate heterozygotes. We believe we are justified in this because heterozygous carriers have methaemoglobin reductase levels about half those of normals (Scott, 1960), and also red cells from cord blood are thought to be weak in their ability to reduce methaemoglobin because of the lower reductase activity in such cells -about half normal levels (Hegesh et al., 1968; Ross, 1963; Vetrella et al., 1971; Kanazawa et al., 1968).

Kaplan et al. (1970) reported a simple spot screening test for the fast detection of red cell NADHdiaphorase deficiency. Their results obtained with heterozygous subjects were not clearcut, and they do not recommend this test for the detection of heterozygotes. The suitability of our method for the detection of the heterozygous trait is suggested by its ability to discriminate better than the standard diaphorase method between cord blood and blood from adults (Fig. 5). The use of the AutoAnalyzer is also an advantage of the method and contributes 
in speed, convenience, and elimination of interference by haemoglobin in spectrophotometry.

The population screened in this investigation ranged from 19 to 71 years of age and few of these subjects had low ferricyanide reductase activity. Two whose blood showed the lowest enzyme activity have, respectively, hypertension treated with trichlormethiazide (Fluitran), hydrallazine (Apresolin), and methoserpidine (Decaserpyl) (59 years old), and hepatoma with pulmonary metastasis ( 71 years old). However, any possible relation between these diseases or therapy and a lower methaemoglobin reductase activity in red blood cells is obscure.

In contrast with the result obtained from adult blood, the detection of the heterozygote in children remains a problem. Detection of the heterozygote in cord and infant blood is very difficult but may become possible by increasing the sensitivity of the method. It should be further investigated in order to measure the reduction rate by the enzyme at $340 \mathrm{~nm}$, the maximum absorption wavelength for NADH, in place of $420 \mathrm{~nm}$ for potassium ferricyanide.

We are grateful to Drs Taiko Ihda and Akemi Sakai, of the Department of Obstetrics and Gynaecology, Kanazawa University Hospital, and to M. T. Kazuko Hashizume and other technologists, of the Central Clinical Laboratory of the same hospital, for the collection of cord blood and blood samples for the screening test. We are also indebted to Dr Masami Hirano, of the Department of Internal Medicine, Medical School of Nagoya Health Science University, who made it possible for us to obtain the blood from the patient with hereditary methaemoglobinaemia. These studies were aided by a Scientific Research Fund (221207) from the Ministry of Education of Japan and supported partly by US-Japan Cooperative Program of the Japanese Society for the Promotion of Science.

\section{References}

Dine, M. S. (1956). Congenital methemoglobinemia in the newborn period. American Journal of Diseases of Children, 92, 15-19.

Fialkow, P. J., Browder, J. A., Sparkes, R. S., and Motulsky, A. G. (1965). Mental retardation in methemoglobinemia due to diaphorase deficiency. New England Journal of Medicine, 273, 840-845.

Gibson, Q. H. (1948). The reduction of methaemoglobin in red blood cells and studies on the cause of idiopathic methaemoglobinaemia. Biochemical Journal, 42, 13-23.

Hegesh, E., Calmanovici, N., and Avron, M. (1968). New method for determining ferrihemoglobin reductase (NADH-methemoglobin reductase) in erythro- cytes. Journal of Laboratory and Clinical Medicine, 72, 339-344.

Hirano, M., Watanabe, E., Kakizawa, H., and Nagamura, Y. (1976). Report of a case of congenital methemoglobinemia with NADH-diaphorase II deficiency. Japanese Journal of Clinical Haematology, 17, 182.

Hsieh, H. S., and Jaffe, E. R. (1975). The metabolism of methemoglobin in human erythrocytes. In The Red Blood Cell, 2nd edition, edited by D. M. Surgenor, Chapter 18, pp. 799-824. Academic Press, New York.

Hultquist, D. E., and Passon, P. G. (1971). Catalysis of methaemoglobin reduction by erythrocyte cytochrome $b_{5}$ and cytochrome $b_{5}$ reductase. Nature (New Biology), 229, 252-254.

Kanazawa, Y., Hattori, M., Kosaka, K., and Nakao, K. (1968). The relationship of NADH-dependent diaphorase activity and methemoglobin reduction in human erythrocytes. Clinica Chimica Acta, 19, 524-526.

Kaplan, J. C., Nicolas, A. M., Hanzlickova-Leroux, A., and Beutler, E. (1970). A simple spot screening test for fast detection of red cell NADH-diaphorase deficiency. Blood, 36, 330-333.

Kuma, F., and Inomata, H. (1972). Studies on methemoglobin reductase. II. The purification and molecular properties of reduced nicotinamide adenine dinucleotide-dependent methemoglobin reductase. Journal of Biological Chemistry, 247, 556-560.

Leroux, A., Junien, C., Kaplan, J. C., and Bamberger, J. (1975). Generalised deficiency of cytochrome $b_{5}$ reductase in congenital methaemoglobinemia with mental retardation. Nature, 258, 619-620.

Ross, J. D. (1963). Deficient activity of DPNH-dependent methemoglobin diaphorase in cord blood erythrocytes. Blood, 21, 51-62.

Scott, E. M. (1960). The relation of diaphorase of human erythrocytes to inheritance of methemoglobinemia. Journal of Clinical Investigation, 39, 1176-1179.

Scott, E. M., and Griffith, I. V. (1959). The enzymic defect of hereditary methemoglobinemia: diaphorase. Biochimica et Biophysica Acta, 34, 584-586.

Sugita, Y., Nomura, S., and Yoneyama, Y. (1971). Purification of reduced pyridine nucleotide dehydrogenase from human erythrocytes and methemoglobin reduction by the enzyme. Journal of Biological Chemistry, 246, 6072-6078.

Tanishima, K., Takeshita, M., Yubisui, T., and Yoneyama, Y. (1978). A colorimetric method for the specific determination of methemoglobin reductase activity in red blood cells. Acta Haematologica Japonica, 40, 695-704.

Vetrella, M., Astedt, B., Barthelmai, W., and Neuvians, D. (1971). Activity of NADH- and NADPH- dependent methemoglobin reductases in erythrocytes from fetal to adult age. Klinische Wochenschrift, 49, 972-977.

Requests for reprints to: Dr Kiyoh Tanishima, Department of Medical Technology, Kanazawa University School of Paramedicine, Kodatsuno 5-11-80, Kanazawa, Japan 920. 